\title{
Protective effects of resveratrol on osteoporosis via activation of the SIRT1-NF-кB signaling pathway in rats
}

\author{
XIAOWEI WANG ${ }^{1,2},{\text { LIAOBIN } \text { CHEN }^{1} \text { and WEI PENG }}^{3}$ \\ ${ }^{1}$ Department of Orthopedics, Zhongnan Hospital of Wuhan University, Wuhan, Hubei 430071; \\ ${ }^{2}$ Department of Orthopedics, The Third People's Hospital of Hubei, Wuhan 430033; ${ }^{3}$ Department of \\ Anesthesiology, Hospital of Stomatology Wuhan University, Wuhan, Hubei 430079, P.R. China
}

Received November 28, 2015; Accepted December 9, 2016

DOI: $10.3892 / \mathrm{etm} .2017 .5147$

\begin{abstract}
The aim of the present study was to determine the protective effects of resveratrol on a rat model of osteoporosis and examine the associated mechanisms of its action. Rats were randomized into the following groups: Control, osteoporosis, osteoporosis + low-dose resveratrol, osteoporosis + middle-dose resveratrol and osteoporosis + high-dose resveratrol groups. Resveratrol treatment was administered 7 days after surgery for 8 weeks. ELISA assay was used to analyze alkaline phosphatase (ALP) and osteocalcin (OC) protein levels. Western blotting was performed to assess the protein expression of sirtuin 1 (SIRT1), nuclear factor (NF)- $\kappa B$ and $N F-\kappa B$ inhibitor (IkB) $\alpha$. In the present study, the results indicated that resveratrol markedly improved the bone mineral density value, femoral porosity and bone mechanical tests in osteoporosis rats. Administration of resveratrol significantly decreased the serum levels of ALP and OC in rats with osteoporosis. Finally, treatment with resveratrol significantly promoted the protein expression of SIRT1, suppressed NF- $\mathrm{B}$ and activated the $\mathrm{IkB} \alpha$ protein expression in rats with osteoporosis. In conclusion, treatment with resveratrol significantly improved the final body weight of the osteoporosis rats via the SIRT1-NF- $\kappa$ B signaling pathway. The present study suggested that resveratrol exerted a protective effect on osteoporosis through activation of the SIRT1-NF- $\mathrm{B}$ signaling pathway in rats.
\end{abstract}

\section{Introduction}

Osteoporosis is a common chronic progressive disease and has the characteristics of osteopenia, bone microstructural damage and bone strength reduction (1). In recent years, the morbidity of osteoporosis has been increasing persistently. Patients with

Correspondence to: Dr Liaobin Chen, Department of Orthopedics, Zhongnan Hospital of Wuhan University, 169 Donghu Road, Wuhan, Hubei 430071, P.R. China

E-mail: zhengjie_40384@163.com

Key words: resveratrol, osteoporosis, sirtuin 1, nuclear factor- $\mathrm{\kappa B}$ osteopenia or osteoporosis in the US are predicted to reach 61 million by 2020 , while patients with osteoporosis that are $>50$ years of age in China had already reached 69.44 million in 2006 (2). Current research has been focusing on the key aspects of osteoporosis, mainly the absorption of bone tissue, and uniform reduction of bone mineral content (3). In addition, bone microstructural damage, increase of osteopsathyrosis, bone load, bending stress and reduction of biomechanical properties also occur in patients with osteoporosis (4). Furthermore, micro fractures or complete fractures can easily occur in osteoporosis patients (4).

The sirtuin 1 (SIRT1) protein was the first member of the Sirtuin protein family to be discovered (5). It has been reported that enzymes associated with SIRT1 are class III histone acetylation enzymes dependent on nicotinamide adenine dinucleotide (NAD ${ }^{+}$), which is highly conserved (6). SIRT1 is able to participate in deacetylation between histone and non-histone lysine residue, and regulates p53, nuclear factor $(\mathrm{NF})-\kappa \mathrm{B}$ and other transcription factors (6). In addition, these genes regulate cell proliferation, differentiation and metabolism, and serve an important regulating effect on chromatin structure, cell metabolism and tumor morbidity processes $(7,8)$. A recent study has identified that SIRT1 also serves an important role in the morbidity and prevention of osteoporosis (6).

Resveratrol is also known as 3,5,4'-trihydroxystilbene and its molecular formula is $\mathrm{C}_{14} \mathrm{H}_{12} \mathrm{O}_{3}$ (Fig. 1), and is a non-flavonoid polyphenolic substance (9). In 1940, it was obtained by separating it from the root of Veratrum grandiflorum for the first time (10). Resveratrol is a natural plant antitoxin that is extracted from numerous spermatophytes in severe environments, including in grapes, berries and peanuts (11). Resveratrol is able to target cytomembranes, intracellular receptors, signaling molecules, enzymes, oxidative system, DNA repair system and transcription factors (12). Cellular signal transduction function is able to convert stimulation into a signal, and this process frequently involves a series of biochemical reactions (13). Resveratrol regulates a series of signal transduction pathways, such as the SIRT1 and NF- $\kappa \mathrm{B}$ signaling pathways (14). Resveratrol is also able to increase the quantity and function of mitochondria (15). Previous studies have demonstrated that various organs, such as the liver, brain, kidney and lung, in F2 hybrid mice appear to have oxidative 
DNA damage with aging $(12,16,17)$. However, the oral absorption of resveratrol may reduce the high levels of oxidative damage markers induced by aging (18). Therefore, the aim of the present study was to investigate the protective effects of resveratrol in a rat model of osteoporosis and examine the associated mechanisms of its action.

\section{Materials and methods}

Animals and osteoporosis model. The procedures of the current study were conducted in accordance with the Principles of Laboratory Animal Care established by the National Institutes of Health (Bethesda, MD, USA) and was approved by the Ethics Committee of Zhongnan Hospital of Wuhan University (Wuhan, China). A total of 46 male Wistar rats (180-200 g; 3-month-old) were obtained from the Animal Experiment Center of Wuhan University and maintained under controlled temperature at $23 \pm 1^{\circ} \mathrm{C}$, humidity of $55 \pm 10 \%$ and a $12 \mathrm{~h}$ light/dark cycle, and food and water were provided ad libitum. An osteotomy was performed in the right femur of each rat according to a previously described method (19). All rats were anesthetized with $30 \mathrm{mg} / \mathrm{kg}$ pentobarbital (intraperitoneally; 69020181; Sinopharm Chemical Reagent Co., Ltd., Shanghai, China), and then surgical procedures were performed, including post-osteotomy fixation and tibia-tail fixation. A lateral approach at the middle of femur was performed, as well as a transverse fracture at the mid-diaphysis, with an oscillating power saw under standard sterile conditions. The fracture site was fixed and steadied by an intramedullary steel needle with a diameter of $1.2 \mathrm{~mm}$ under sterilized sutures.

Experimental groups. Rats were randomized into the following groups: Control ( $\mathrm{n}=6$, sham operation), osteoporosis $(\mathrm{n}=10)$, osteoporosis + low-dose resveratrol $(5 \mathrm{mg} / \mathrm{kg} ; \mathrm{n}=10)$, osteoporosis + middle-dose resveratrol $(25 \mathrm{mg} / \mathrm{kg} ; \mathrm{n}=10)$ and osteoporosis + high-dose resveratrol $(45 \mathrm{mg} / \mathrm{kg} ; \mathrm{n}=10)$ groups. Resveratrol (Sigma-Aldrich; Merck KGaA, Darmstadt, Germany) treatment was provided at 7 days after surgery for 8 weeks, and control and osteoporosis group were was provided with normal saline.

Measurement of $B M D$. All rats were scanned with a dual-energy X-ray absorptiometry system (Norland XR-46; Norland at Swissray, Fort Atkinson, WI, USA) according to a previous method (20). Briefly, the bone mineral density (BMD) value was measured for the proximal third of the right tibia at a scan pitch of $1.5 \mathrm{~mm}$ and a scan speed of $60 \mathrm{~mm} / \mathrm{sec}$. The whole femur was divided into three equal fields for X-ray analysis, which included the distal femoral epiphysis and femoral shaft.

Histological analysis. All rats were sacrificed using decollation under $30 \mathrm{mg} / \mathrm{kg}$ pentobarbital and bone samples from the right proximal tibias were harvested. Bone samples were subsequently fixed with $4 \%$ formaldehyde for $24 \mathrm{~h}$ and dehydrated in a graded ethanol series, cleared in xylene and embedded in molten paraffin at $62^{\circ} \mathrm{C}$ overnight. Blocks were cut into $4-\mu \mathrm{m}$ sections. Subsequently, the sections were stained with hematoxylin and eosin and analyzed with Image-Pro Plus software (version 6.0; Media Cybernetics, Inc., Rockville, MD, USA).

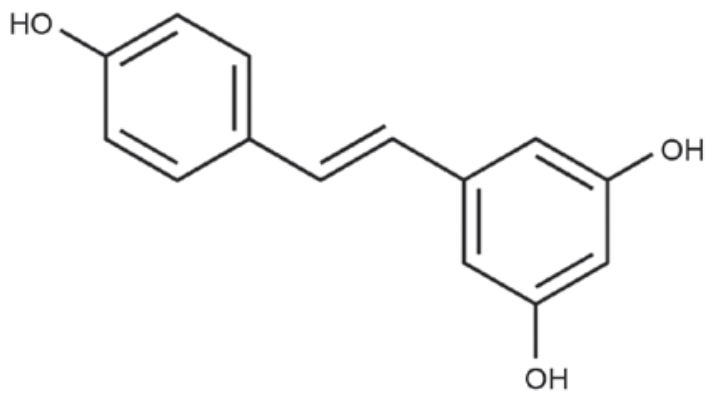

Figure 1. Chemical structure of resveratrol.

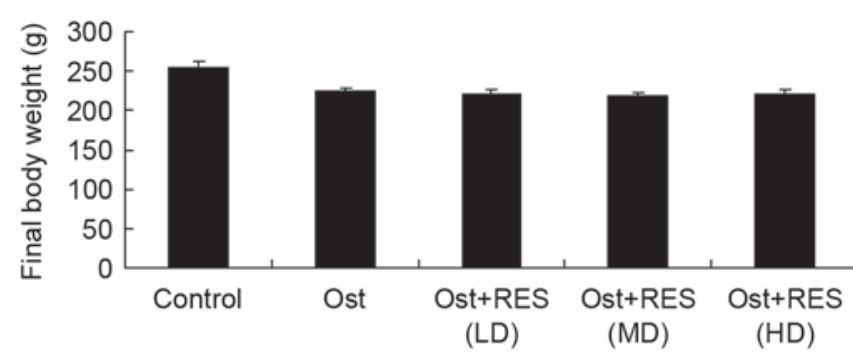

Figure 2. Final body weight of rats in the various experimental groups. The weight was comparable among the groups with no significant differences. Ost, osteoporosis; RES, resveratrol; LD, low-dose; MD, middle-dose; HD, high-dose.

ELISA assay of alkaline phosphatase (ALP) and osteocalcin $(O C)$ protein levels. Blood samples $(2 \mathrm{ml})$ were collected from the right common carotid artery following resveratrol treatment and centrifuged at a speed of $3,000 \mathrm{x}$ g at $4^{\circ} \mathrm{C}$ for $20 \mathrm{~min}$. The serum levels of ALP (E-EL-R0113c) and OC (E-EL-R0243c) were measured by colorimetric analysis at $450 \mathrm{~nm}$, according to the manufacturer's instructions (Elabscience Biotechnology Co., Ltd., Wuhan, China).

Bone mechanical tests. All bone samples were assessed for femur strength by the three-point bending test according to a previous method (20). The femur of each rat was removed from storage at $-80^{\circ} \mathrm{C}$, and lengths were measured using a caliper. The hydrated weight of the bones was determined using a four decimal place digital scale. Specimens were placed on two supports $(12 \mathrm{~mm})$ and bent until fractured by lowering the crosshead positioned at the mid-shaft. The peak load $(\mathrm{N})$ and the ultimate stiffness $(\mathrm{N} / \mathrm{mm})$ were obtained from the load placement curve.

Western blot assay. Bone samples from the right proximal tibias were homogenized and lysed in ice-cold RIPA buffer containing $1 \%$ protease inhibitor cocktail (Sigma-Aldrich; Merck KGaA). The supernatant was collected after centrifugation at $12,000 \mathrm{x} \mathrm{g}$ for $20 \mathrm{~min}$ at $4^{\circ} \mathrm{C}$, and the protein concentration was measured by the modified Bradford assay (Bio-Rad Laboratories, Inc., Hercules, CA, USA). Protein samples $(50 \mu \mathrm{g})$ were then separated by $8-12 \%$ SDS-PAGE and transferred to nitrocellulose membranes (EMD Millipore, Billerica, MA, USA). Next, membranes were blocked with 5\% non-fat milk in Tris-buffered saline with $0.1 \%$ Tween-20 ( $\mathrm{pH}$ 7.4) for $2 \mathrm{~h}$ at room temperature. Membranes were probed 


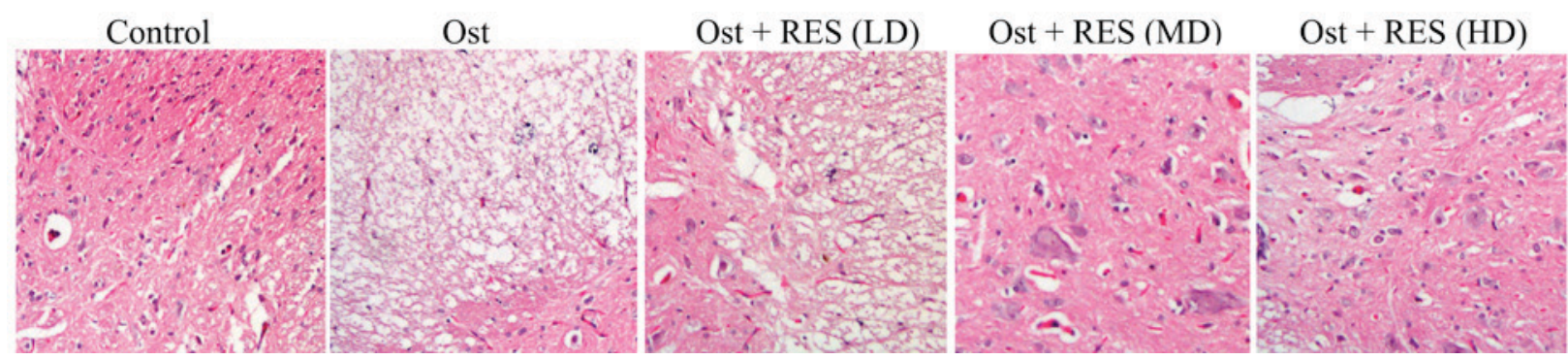

Figure 3. Histological images showing the bone mineral density in each experimental group, obtained following hematoxylin and eosin staining. Magnification, $\mathrm{x} 40$. Ost, osteoporosis; RES, resveratrol; LD, low-dose; MD, middle-dose; HD, high-dose.

overnight at $4^{\circ} \mathrm{C}$ with the following primary antibodies: Anti-SIRT1 (sc-15404; 1:4,000), anti-NF-kB (sc-109, 1:200), anti-IkB $\alpha$ (sc-9130, 1:400) and anti- $\beta$-actin (sc-7210, 1:2,000; all from Santa Cruz Biotechnology, Inc., Dallas, TX, USA). This was followed by incubation with the corresponding horseradish peroxidase-conjugated anti-rabbit secondary antibodies (sc-2357; 1:2,000; Santa Cruz Biotechnology, Inc.) at room temperature for $1 \mathrm{~h}$. The western blot bands were detected using an enhanced chemiluminescence reagent kit (EMD Millipore) and visualized with UVP 210 Bio-Imaging Systems (UVP, Upland, CA, USA).

Statistical analysis. All data are expressed as the mean \pm standard deviation. The control and treated groups were compared using one-way analysis of variance. Statistically significant differences between the results were analyzed using the SPSS software (version 15.0; SPSS, Inc., Chicago, IL, USA), and were indicated by $\mathrm{P}<0.05$.

\section{Results}

Final body weight. The final body weights of the rats in each group were compared. As shown in Fig. 2, the results indicated that the normal control group had a slightly higher body weight compared with that of the other experimental groups; however, there were no significant differences in body weight between any groups (Fig. 2).

Histological analysis of BMD. Compared with the normal control group, the BMD was evidently lower and a cavity was observed in the osteoporosis group (Fig. 3). There were no considerable differences between the osteoporosis and low-dose resveratrol groups (Fig. 3). By contrast, the BMD was markedly increased by treatment with middle-dose or high-dose resveratrol in osteoporosis rats (Fig. 3).

$B M D$ value. In the osteoporosis group, the BMD value was significantly decreased compared with that in the normal control group (Fig. 4; $\mathrm{P}=0.0031$ ). However, there were no significantly differences between the osteoporosis and low-dose resveratrol groups (Fig. 4). Treatment with middle-dose or high-dose resveratrol significantly increased the $\mathrm{BMD}$ value in the osteoporosis rats (Fig. 4; $\mathrm{P}=0.0065$, $\mathrm{P}=0.0043$, respectively).

Serum levels of ALP and OC. Analysis of blood samples by ELISA identified that the serum levels of ALP $(\mathrm{P}=0.0027)$ and $\mathrm{OC}(\mathrm{P}=0.0022)$ in the osteoporosis group were higher compared with those of the normal control group (Fig. 5). However, no significant changes were detected between the osteoporosis and low-dose resveratrol group (Fig. 5). As shown in Fig. 5, middle-dose or high-dose resveratrol treatment significantly inhibited the serum levels of ALP ( $\mathrm{P}=0.0087$ and $\mathrm{P}=0.0077$, respectively) and $\mathrm{OC}(\mathrm{P}=0.0076$ and $\mathrm{P}=0.0061$, respectively) in the osteoporosis rats.

Femoral porosity. When compared with the normal control group, pixel intensity (distal, mid-shaft and proximal epiphysis) was evidently enhanced in the osteoporosis group (Fig. 6; $\mathrm{P}=0.0034, \mathrm{P}=0.0069$ and $\mathrm{P}=0.0041$, respectively). No significant intergroup difference was observed between the osteoporosis and low-dose resveratrol groups for pixel intensity in osteoporosis rats (Fig. 6). Furthermore, treatment with middle- or high-dose resveratrol significantly reduced the pixel intensity (distal, mid-shaft and proximal epiphysis) in the osteoporosis rats (Fig. 6; $\mathrm{P}=0.0081$ and $\mathrm{P}=0.0062 ; \mathrm{P}=0.0093$ and $\mathrm{P}=0.0078 ; \mathrm{P}=0.0087$ and $\mathrm{P}=0.0067$, respectively).

Bone mechanical tests. The present study found that there was a significant inhibition in the percentages of peak load and ultimate stiffness in the osteoporosis group compared with the normal control group (Fig. 7; P=0.0044, $\mathrm{P}=0.0078$ ). However, there was no significant difference between the osteoporosis and low-dose resveratrol groups (Fig. 7). By contrast, treatment with middle- or high-dose resveratrol significantly inhibited the percentages of peak load and ultimate stiffness in the osteoporosis rats, as shown in Fig. $7(\mathrm{P}=0.0062, \mathrm{P}=0.038$; $\mathrm{P}=0.0081, \mathrm{P}=0.0073$ ).

Treatment effect on SIRT1 signaling pathway. Western blot assay was performed to measure the protein expression of SIRT1 in the rat tissues. As shown in Fig. 8, there was no significant difference in the SIRT1 protein levels among the normal control, osteoporosis and low-dose resveratrol groups. By contrast, treatment with middle-dose or high-dose resveratrol significantly activated the protein expression of SIRT1 in the osteoporosis rats (Fig. 8, $\mathrm{P}=0.0076, \mathrm{P}=0.0048$ ).

Treatment effect on $N F-\kappa B$ signaling pathway. As shown in Fig. 9, the protein expression of NF- $\mathrm{kB} / \mathrm{p} 65$ in the normal control group was very similar to that in the osteoporosis or low-dose resveratrol groups $(\mathrm{P}=0.4368, \mathrm{P}=0.0562)$. However, middle-dose or high-dose resveratrol significantly suppressed 


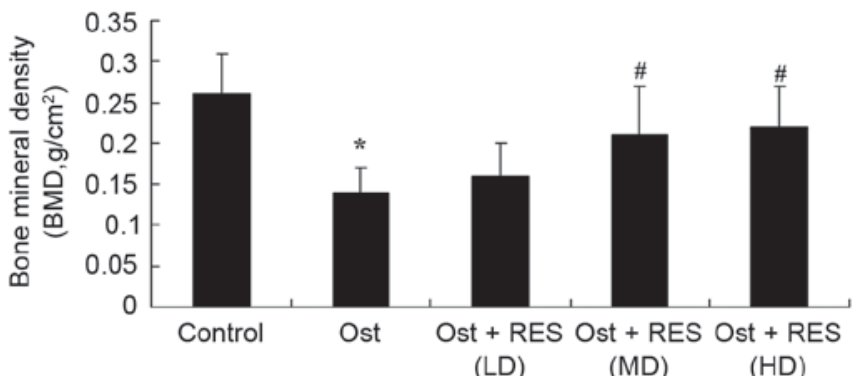

Figure 4. BMD values in the experimental group, showing increased BMD in the RES (MD) and RES (HD) groups. ${ }^{~} \mathrm{P}<0.01$ vs. control group; ${ }^{~} \mathrm{P}<0.01$ vs. Ost group. BMD, bone mineral density; Ost, osteoporosis; RES, resveratrol; LD, low-dose; MD, middle-dose; HD, high-dose.
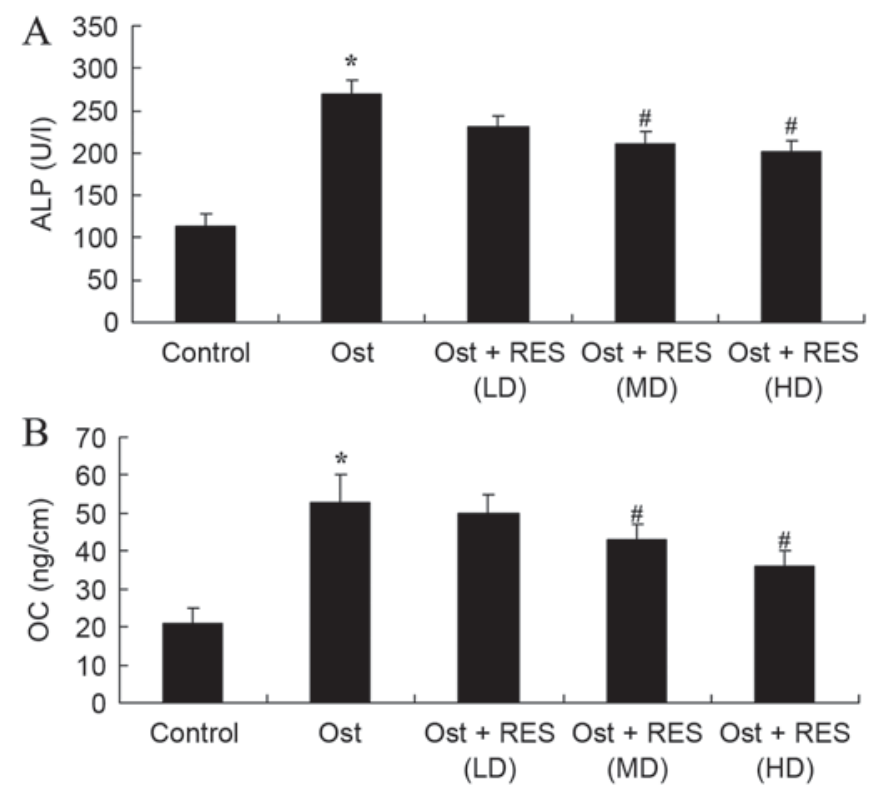

Figure 5. Serum levels of (A) ALP and (B) OC in osteoporosis rats, as determined by ELISA. " $\mathrm{P}<0.01$ vs. control group; ${ }^{~} \mathrm{P}<0.01$ vs. Ost group. ALP, alkaline phosphatase; OC, osteocalcin; Ost, osteoporosis; RES, resveratrol; LD, low-dose; MD, middle-dose; HD, high-dose.

the protein expression of $\mathrm{NF}-\mathrm{kB} / \mathrm{p} 65$ in the osteoporosis rats (Fig. 9; $\mathrm{P}=0.0036, \mathrm{P}=0.0013$ ).

Treatment effect on IkB $\alpha$ signaling pathway. As revealed by the western blot results, there was no significant difference in the IkBa protein expression levels among the normal control, osteoporosis and low-dose resveratrol groups (Fig. 10). However, middle-dose or high-dose resveratrol treatment significantly promoted the protein expression of $\mathrm{IkB} \alpha$ in the osteoporosis rats (Fig. 10; $\mathrm{P}=0.0051, \mathrm{P}=0.0037$ ).

\section{Discussion}

As one of the diseases predominantly presenting in the elderly, an increasing number of individuals suffer from osteoporosis and osteoporotic fractures as a result of the increase in the elderly population (21). Osteoporosis has already become a problem for healthcare in the aging population; however, it has yet to attract sufficient research attention (22). The morbidity of osteoporosis progresses rapidly and has become a common
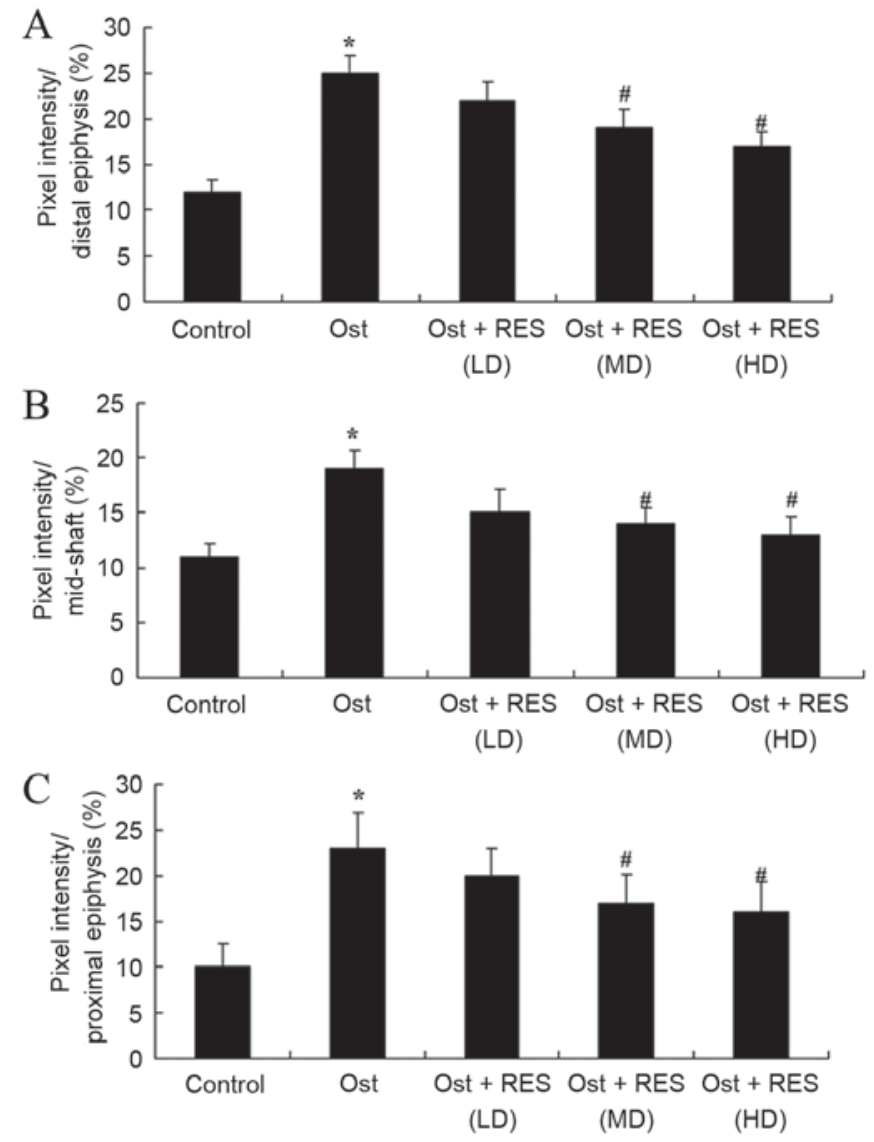

Figure 6. Femoral porosity based on the pixel intensity of (A) proximal, (B) mid-shaft and (C) proximal epiphysis in osteoporosis rats. " $\mathrm{P}<0.01$ vs. control group; ${ }^{\mathrm{P}} \mathrm{P}<0.01$ vs. Ost group. Ost, osteoporosis; RES, resveratrol; LD, low-dose; MD, middle-dose; HD, high-dose.

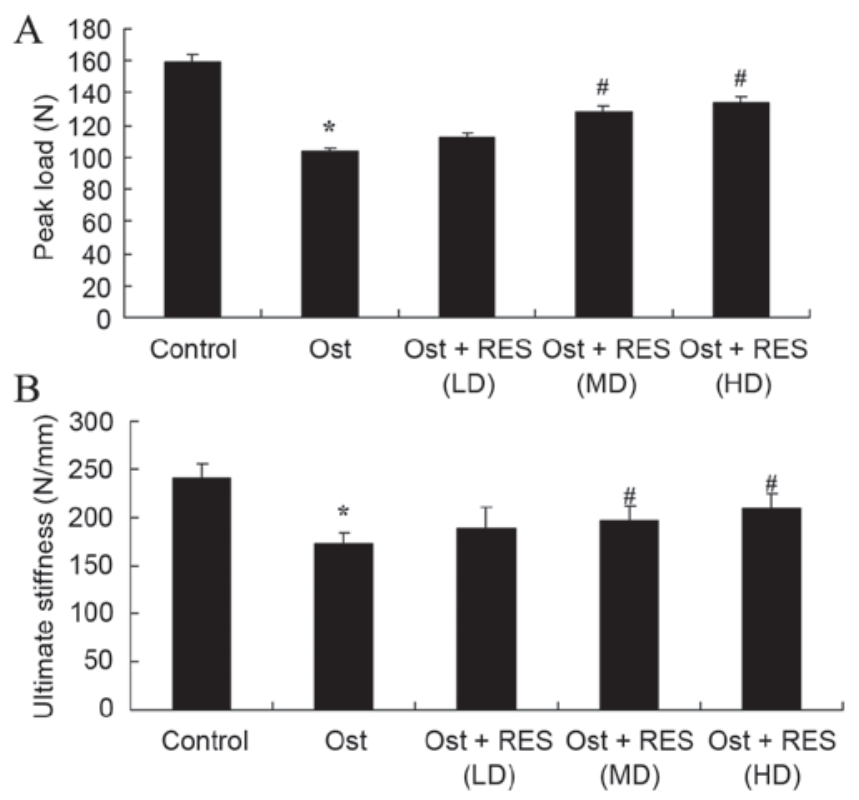

Figure 7. Bone mechanical tests, showing the percentages of (A) peak load and (B) ultimate stiffness of the femur in osteoporosis rats. "P $<0.01$ vs. control group; ${ }^{~} \mathrm{P}<0.01$ vs. Ost group. Ost, osteoporosis; RES, resveratrol; LD, low-dose; MD, middle-dose; HD, high-dose.

disease in the elderly, due to the rapid development of social civilization and economy, growth in the living standards, and 

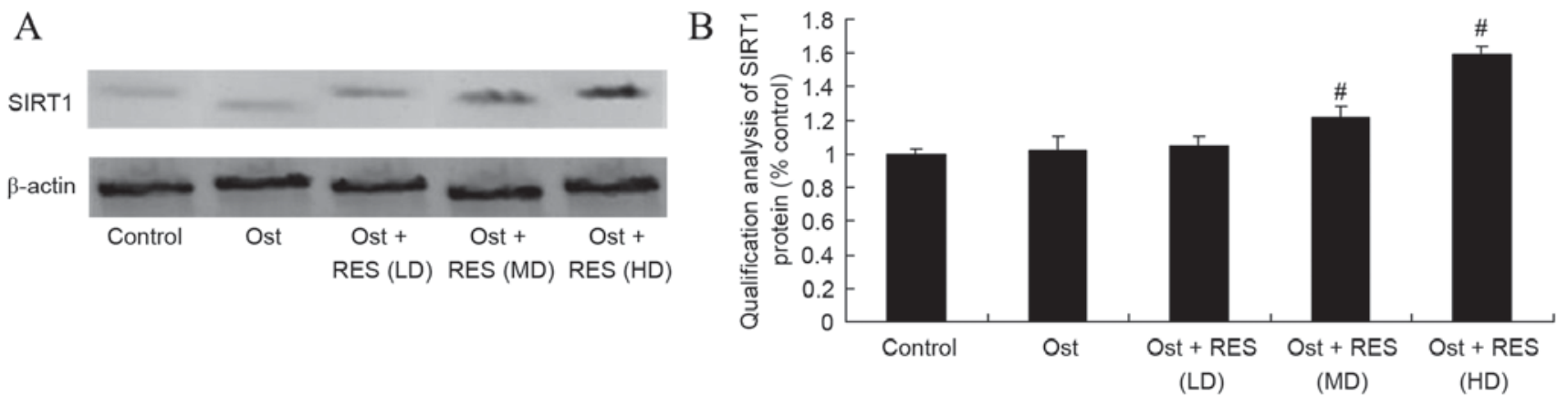

Figure 8. SIRT1 protein expression, determined by western blot analysis. (A) The western blots and (B) the quantified results of SIRT1 protein expression are shown. " P<0.01 vs. Ost group. SIRT1, sirtuin 1; Ost, osteoporosis; RES, resveratrol; LD, low-dose; MD, middle-dose; HD, high-dose.
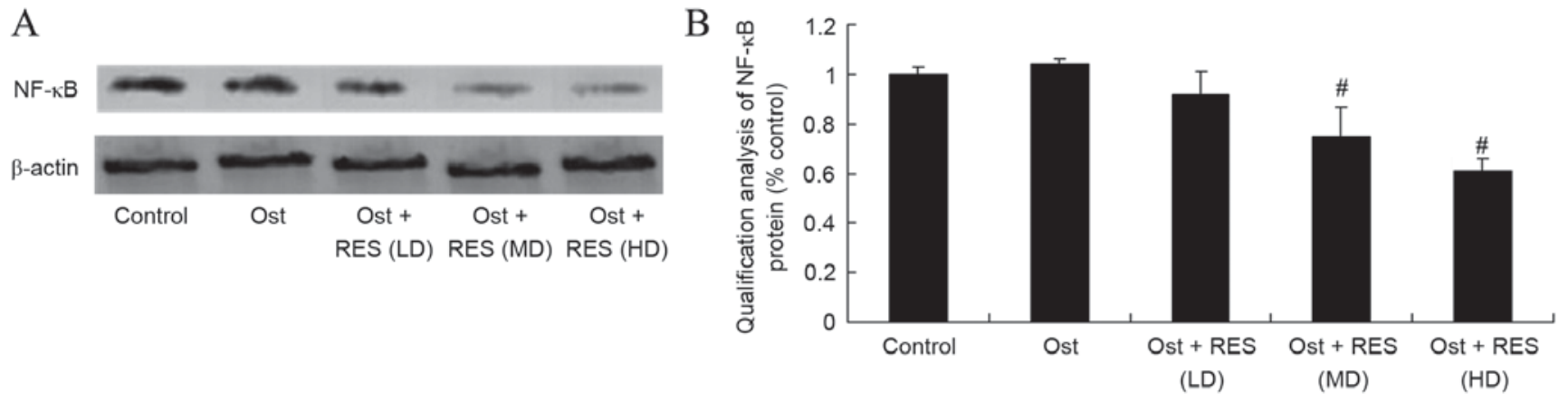

Figure 9. Western blot analysis of NF- $\mathrm{kB}$ protein expression as shown in the (A) western blots and (B) quantified levels. " $\mathrm{P}<0.01$ vs. Ost group. Ost, osteoporosis; RES, resveratrol; LD, low-dose; MD, middle-dose; HD, high-dose.
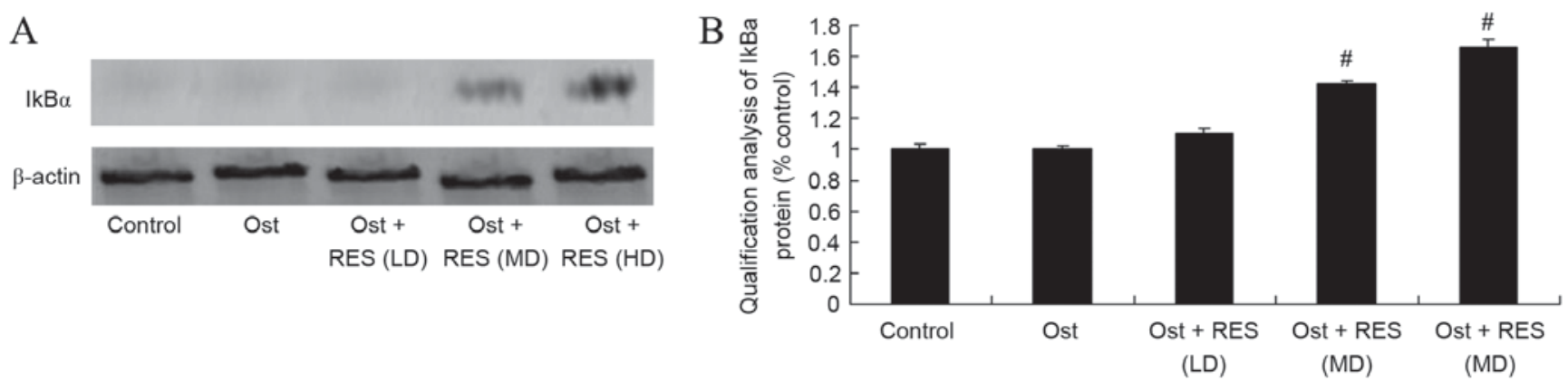

Figure 10. Western blot analysis of IkB $\alpha$ protein expression as shown in the (A) western blots and (B) quantified levels. "P<0.01 vs. Ost group. Ost, osteoporosis; RES, resveratrol; LD, low-dose; MD, middle-dose; HD, high-dose.

changes of life styles and habits, particularly in cities and areas with increasing aging of population (23). In the present study, it was verified that treatment with middle-dose or high-dose resveratrol markedly increased the BMD in osteoporosis rats. The study by Zhao et al (12) previously reported that resveratrol suppresses the excess-iron-induced bone loss through its antioxidative ability.

The bone matrix includes organic and inorganic matter. Organic matter mainly contains collagenous fibers (primarily types I and II collagenous fibers) and a few amorphous matrixes (24). Inorganic matter is referring to bone minerals, and includes the crystalline hydroxyapatite and amorphous colloidal calcium phosphorus. Collagenous fibers are matrix proteins that constitute the bone structure and maintain the bone mechanical strength (25). Thus, bone formation is equivalent to bone mineralization, and refers to the process through which amorphous calcium phosphate and its bone mineral are deposited in bone organic matter intervals regularly (26). Ossein, referring to the collagen content of bones, is the core of bone mineralization. In addition, estrogen promotes the secretion of type I osteoblast collagen, alkaline phosphatase and transforming growth factor, so as to promote bone formation (27). The current study found that resveratrol treatment significantly inhibited the serum levels of ALP and OC in osteoporosis rats. Similarly, Lee et al (14) have previously suggested that resveratrol promoted bone growth through the mediation of ALP levels in young rats.

SIRT1 is closely associated with bone metabolism and bone mass. Histone is able to restrain bone formation, reduce the expression of OC and ALP in osteoblasts, and reduce the proliferation and differentiation of osteoblasts (28). The 
current osteoporosis medicines for prevention, particularly traditional Chinese medicines, mainly promote proliferation and differentiation of osteoblasts $(29,30)$. The inhibition of SIRT1 expression is important for osteoporosis and for improving the BMD in old-age mice. It has been shown that resveratrol, an activator of SIRT1 can improve the differentiation of osteoblasts, as well as reduce the formation of marrow adipose cells and the quantity of osteoclasts (29). In the present study experiments, treatment with resveratrol significantly activated the protein expression of SIRT1 in osteoporosis rats. Sin et al supported that resveratrol has an effect on muscle injury induced by compression through SIRT1 protein expression (31). Lee et al (14) also showed that resveratrol induces human keratinocyte damage through the activation of SIRT1 (14).

$\mathrm{NF}-\kappa \mathrm{B}$ is closely associated with bone metabolism. Reduction of NF- $\kappa \mathrm{B}$ activity in osteoblasts can strengthen bone cellular differentiation and mineralization, and reinforce bone formation (32). It has been shown that $N F-\kappa B$ activation depends on the phosphorylation of $\mathrm{NF}-\kappa \mathrm{B} / \mathrm{p} 65$. However, genes that regulate $N F-\kappa B$ in osteoblasts directly need to be confirmed (33). Apoptosis of osteoblasts can increase the generation of cancellous bone, and previous research findings revealed that apoptosis in mice with diabetes was evidently increased. The NF- $\mathrm{B}$ pathway of osteoclasts has already been widely studied (34). RANKL, TNF- $\alpha$ or IL-1 activated NF- $\kappa$ B signal pathway can induce differentiation gene expression of osteoclasts, lengthen the life of osteoclasts and increase bone absorption (35). The present study has clearly demonstrated that resveratrol significantly suppressed the protein expression of $\mathrm{NF}-\kappa \mathrm{B} / \mathrm{p} 65$ and activated $\mathrm{IkB} \alpha$ protein expression in osteoporosis rats. Similarly, Zhang et al (32) reported that resveratrol attenuates liver fibrosis through the suppression of $\mathrm{NF}-\kappa \mathrm{B}$.

In conclusion, the present study confirmed that resveratrol significantly increases BMD, and inhibits the percentages of peak load and ultimate stiffness in osteoporosis rats. An important finding is that the beneficial effects of resveratrol also inhibited the serum levels of ALP and OC in osteoporosis rats, in which mediated by SIRT1- NF- $\kappa$ B signaling pathway. In future studies, the molecular mechanisms behind resveratrol-associated protein regulation require further investigation.

\section{References}

1. Mattei TA, Rehman AA, Issawi A and Fassett DR: Surgical challenges in the management of cervical kyphotic deformity in patients with severe osteoporosis: An illustrative case of a patient with Hajdu-Cheney syndrome. Eur Spine J 24: 2746-2753, 2015.

2. Ohtori S, Akazawa T, Murata Y, Kinoshita T, Yamashita M, Nakagawa K, Inoue G, Nakamura J, Orita S, Ochiai N, et al: Risedronate decreases bone resorption and improves low back pain in postmenopausal osteoporosis patients without vertebral fractures. J Clin Neurosci 17: 209-213, 2010.

3. Otrock ZK, Azar ST, Shamseddeen WA, Habr D, Inati A, Koussa S, Mahfouz RA and Taher AT: Intravenous zoledronic acid treatment in thalassemia-induced osteoporosis: Results of a phase II clinical trial. Ann Hematol 85: 605-609, 2006.

4. Bastian L, Schils F, Tillman JB and Fueredi G; SCORE Investigators: A randomized trial comparing 2 techniques of balloon kyphoplasty and curette use for obtaining vertebral body height restoration and angular-deformity correction in vertebral compression fractures due to osteoporosis. AJNR Am J Neuroradiol 34: 666-675, 2013.
5. Jiang Y, Zeng Y, Huang X, Qin Y, Luo W, Xiang S, Sooranna SR and Pinhu L: Nur77 attenuates endothelin-1 expression via downregulation of NF- $\mathrm{kB}$ and $\mathrm{p} 38$ MAPK in A549 cells and in an ARDS rat model. Am J Physiol Lung Cell Mol Physiol 311: L1023-L1035, 2016.

6. Dvir-Ginzberg $\mathrm{M}$ and Steinmeyer J: Towards elucidating the role of SirT1 in osteoarthritis. Front Biosci (Landmark Ed) 18: 343-355, 2013.

7. Bai B, Vanhoutte PM and Wang Y: Loss-of-SIRT1 function during vascular ageing: Hyperphosphorylation mediated by cyclin-dependent kinase 5. Trends Cardiovasc Med 24: 81-84, 2014.

8. Jung-Hynes B and Ahmad N: SIRT1 controls circadian clock circuitry and promotes cell survival: A connection with age-related neoplasms. FASEB J 23: 2803-2809, 2009.

9. Javkhedkar AA and Banday AA: Antioxidant resveratrol restores renal sodium transport regulation in SHR. Physiol Rep 3: pii: e12618, 2015

10. McGill MR, Du K, Weemhoff JL and Jaeschke H: Critical review of resveratrol in xenobiotic-induced hepatotoxicity. Food Chem Toxicol 86: 309-318, 2015.

11. Shankar S, Singh G and Srivastava RK: Chemoprevention by resveratrol: Molecular mechanisms and therapeutic potential. Front Biosci 12: 4839-4854, 2007.

12. Zhao L, Wang Y, Wang Z, Xu Z, Zhang Q and Yin M: Effects of dietary resveratrol on excess-iron-induced bone loss via antioxidative character. J Nutr Biochem 26: 1174-1182, 2015.

13. Szkudelski T and Szkudelska K: Resveratrol and diabetes: From animal to human studies. Biochim Biophys Acta 1852: 1145-1154, 2015.

14. Lee JH, Kim JS, Park SY and Lee YJ: Resveratrol induces human keratinocyte damage via the activation of class III histone deacetylase, Sirt1. Oncol Rep 35: 524-529, 2016.

15. Kumar S, Eroglu E, Stokes JA III, Scissum-Gunn K, Saldanha SN, Singh UP, Manne U, Ponnazhagan S and Mishra MK: Resveratrol induces mitochondria-mediated, caspase-independent apoptosis in murine prostate cancer cells. Oncotarget 8: 20895-20908, 2017.

16. Lopez MS, Dempsey RJ and Vemuganti R: Resveratrol neuroprotection in stroke and traumatic CNS injury. Neurochem Int 89: 75-82, 2015.

17. de Ligt M, Timmers S and Schrauwen P: Resveratrol and obesity: Can resveratrol relieve metabolic disturbances? Biochim Biophys Acta 1852: 1137-1144, 2015.

18. Ozcicek A, Cetin N, Keskin Cimen F, Tumkaya L, Malkoc I, Gulaboglu M, Yarali O and Suleyman B: The impact of resveratrol on oxidative stress induced by methotrexate in rat ileum tissue: Evaluation of biochemical and histopathological features and analysis of gene expression. Med Princ Pract 25: 181-186, 2016.

19. Mathavan N, Bosemark P, Isaksson H and Tägil M: Investigating the synergistic efficacy of BMP-7 and zoledronate on bone allografts using an open rat osteotomy model. Bone 56: 440-448, 2013.

20. Khajuria DK, Razdan R, Mahapatra DR and Bhat MR: Osteoprotective effect of propranolol in ovariectomized rats: A comparison with zoledronic acid and alfacalcidol. J Orthop Sci 18: 832-842, 2013.

21. Gamsjaeger S, Buchinger B, Zwettler E, Recker R, Black D, Gasser JA, Eriksen EF, Klaushofer K and Paschalis EP: Bone material properties in actively bone-forming trabeculae in postmenopausal women with osteoporosis after three years of treatment with once-yearly Zoledronic acid. J Bone Miner Res 26: 12-18, 2011.

22. Haines CJ, Chung TK, Leung PC, Hsu SY and Leung DH: Calcium supplementation and bone mineral density in postmenopausal women using estrogen replacement therapy. Bone 16: 529-531, 1995.

23. Wang T, Pang L, Huang H and Wang WY: Observation on influence of bone metabolism biochemical indices of senile osteoporosis treated with distant acupuncture and nearby tuina. Zhongguo Zhen Jiu 32: 13-16, 2012 (In Chinese).

24. Pedraza CE, Marelli B, Chicatun F, McKee MD and Nazhat SN: An in vitro assessment of a cell-containing collagenous extracellular matrix-like scaffold for bone tissue engineering. Tissue Eng Part A 16: 781-793, 2010.

25. Reid JW, Pietak A, Sayer M, Dunfield D and Smith TJ: Phase formation and evolution in the silicon substituted tricalcium phosphate/apatite system. Biomaterials 26: 2887-2897, 2005.

26. Levaot N, Simoncic PD, Dimitriou ID, Scotter A, La Rose J, $\mathrm{Ng}$ AH, Willett TL, Wang CJ, Janmohamed S, Grynpas M, et al: 3BP2-deficient mice are osteoporotic with impaired osteoblast and osteoclast functions. J Clin Invest 121: 3244-3257, 2011. 
27. Now warote N, Osathanon T, Jitjaturunt P, Manopattanasoontorn S and Pavasant P: Asiaticoside induces type I collagen synthesis and osteogenic differentiation in human periodontal ligament cells. Phytother Res 27: 457-462, 2013.

28. He N, Zhu X, He W, Zhao S, Zhao W and Zhu C: Resveratrol inhibits the hydrogen dioxide-induced apoptosis via Sirt 1 activation in osteoblast cells. Biosci Biotechnol Biochem 79: 1779-1786, 2015.

29. Shakibaei M, Shayan P, Busch F, Aldinger C, Buhrmann C, Lueders $C$ and Mobasheri A: Resveratrol mediated modulation of Sirt-1/Runx2 promotes osteogenic differentiation of mesenchymal stem cells: Potential role of Runx2 deacetylation. PLoS One 7: e35712, 2012.

30. Saravanan S, Vimalraj S, Vairamani M and Selvamurugan N: Role of mesoporous wollastonite (Calcium Silicate) in mesenchymal stem cell proliferation and osteoblast differentiation: A cellular and molecular study. J Biomed Nanotechnol 11: $1124-1138,2015$

31. Sin TK, Yung BY, Yip SP, Chan LW, Wong CS, Tam EW and Siu PM: SIRT1-dependent myoprotective effects of resveratrol on muscle injury induced by compression. Front Physiol 6: 293, 2015 .
32. Zhang F, Lu M, Wang $\mathrm{H}$ and Ren T: Aspirin attenuates angiotensin II-induced inflammation in bone marrow mesenchymal stem cells via the inhibition of ERK1/2 and NF- $\mathrm{BB}$ activation. Biomed Rep 1: 930-934, 2013.

33. Wu CM, Chen PC, Li TM, Fong YC and Tang CH: Si-Wu-tang extract stimulates bone formation through PI3K/Akt/NF- $\kappa \mathrm{B}$ signaling pathways in osteoblasts. BMC Complement Altern Med 13: 277, 2013.

34. Yao Z, Li Y, Yin X, Dong Y, Xing L and Boyce BF: NF-кB RelB negatively regulates osteoblast differentiation and bone formation. J Bone Miner Res 29: 866-877, 2014.

35. Tsubaki M, Takeda T, Kino T, Itoh T, Imano M, Tanabe G, Muraoka O, Satou T and Nishida S: Mangiferin suppresses CIA by suppressing the expression of TNF- $\alpha$, IL- 6 , IL-1 $\beta$ and RANKL through inhibiting the activation of NF- $\mathrm{KB}$ and ERK1/2. Am J Transl Res 7: 1371-1381, 2015. 